\title{
CARACTERÍSTICAS FÍSICAS E SENSORIAIS DE CLONES DE BATATA-DOCE
}

\author{
Physical and sensorial characteristics of sweetpotato clones
}

\author{
Adriana Dias Cardoso ${ }^{1}$, Anselmo Eloy Silveira Viana ${ }^{2}$, Sylvana Naomi Matsumoto ${ }^{2}$, \\ Hermes Bomfim Neto ${ }^{3}$,Camila Rodrigues Khouri, ${ }^{4}$ Thiago Lima Melo ${ }^{5}$
}

\begin{abstract}
RESUMO
Com o objetivo de avaliar propriedades físicas e sensoriais de clones de batata-doce em Vitória da Conquista - BA foi realizado este experimento, composto por 16 clones oriundos de Janaúba- G, Viçosa -MG, Bom Jardim de Minas - MG, Gurupi TO, Santo Antônio da Platina - PR, Holambra II - SP, Vitória da Conquista - BA e Condeúba - BA. Utilizou-se o delineamento em blocos casualizados, com 16 tratamentos e 3 repetições. Avaliaram-se as características sensoriais: aparência, umidade, doçura, coloração da polpa, dificuldade de deglutição das raízes tuberosas e as características físicas: tempo de cozimento e peso específico. Os dados foram submetidos à análise de variância e teste de Scott-Knott a 5\% de probabilidade, entretanto, as características sensoriais foram obtidas apenas em valores de porcentagem. O clone 25 apresentou as melhores características sensoriais e o clone 7 apresentou melhor tempo de cozimento.
\end{abstract}

Termos para indexação: Ipomoea batatas (L.) Lam., análise sensorial, cozimento.

\section{ABSTRACT}

The aim of this experiment was to evaluate the physical and sensorial characteristics of sweetpotato clones in Vitória da Conquista, Bahia State, Brazil. Sixteen clones were analyzed, originating from Janaúba, MG, Viçosa, MG; Bom Jardim de Minas, MG; Gurupi, TO; Santo Antônio da Platina, PR; Holambra II, SP; Vitória da Conquista, BA; and Condeúba, BA. One utilized randomized blocks with 16 treatments and three repetitions. The following characteristics were analyzed: aspect, humidity, sweetness, color, deglutition difficulty, cooking and specific gravity of the storage roots. The data were submitted to variance analysis using a Scott-Knott test with $5 \%$ probability. Clone 25 presented the best sensorial characteristics, and clone 7 presented the best cooking time.

Index terms: Ipomoea batatas (L.) Lam., sensory analysis, cooking.

(Recebido em 9 de março de 2006 e aprovado em 11 de junho de 2007)

\section{INTRODUÇÃO}

A batata-doce (Ipomoea batatas (L.) Lam.) é uma hortaliça frequentemente cultivada em países em desenvolvimento, inclusive no Brasil, especialmente no Nordeste, onde constitui a principal hortaliça consumida. É plantada por pequenos produtores, sendo considerada muito rústica e pouco exigente, razão da escassez de estudos e investimentos tecnológicos para o melhor aproveitamento do seu potencial agronômico (MIRANDA et al., 1987).

Segundo Miranda et al. (1995), o potencial de produção da batata-doce é alto por ser uma das plantas com maior capacidade de produzir energia por unidade de área e tempo (Kcal/ha/dia). As ramas e raízes tuberosas são largamente utilizadas na alimentação humana, animal e também como matéria-prima nas indústrias de alimento, tecido, papel, cosmético, preparação de adesivos e álcool carburante. Seu consumo per capita é bastante variado: desde $2 \mathrm{~kg} / \mathrm{hab} / \mathrm{ano}$, nos Estados Unidos a 114kg/hab/ ano no Burundi (CIP, 2001).

O Brasil é o décimo quinto produtor mundial de batata-doce, com aproximadamente 500.000 toneladas/ ano, em uma área plantada de 48.000 hectares, com produtividade média de $11.219 \mathrm{~kg} /$ hectare (FAO, 2007).

Conforme Murilo (1999), a batata-doce é a quarta hortaliça mais consumida pela população brasileira, com média de 3,6 kg/hab/ano, superada apenas pela batata, tomate e abóbora. Conforme Miranda et al. (1989), para as regiões Sul e Nordeste, o referido consumo, corresponde a 5,6 e $6,8 \mathrm{~kg}$, respectivamente.

\footnotetext{
'Engenheira Agrônoma, Doutora - Departamento de Fitotecnia e Zootecnia/DFZ - Universidade Estadual do Sudoeste da Bahia/UESB - Estrada do BemQuerer, Km 04 - Bairro Universitário - 45083-900 - Vitória da Conquista, BA - adriadk@bol.com.br

${ }^{2}$ Doutores, Professores Titular - Departamento de Fitotecnia e Zootecnia/DFZ - Universidade Estadual do Sudoeste da Bahia/UESB - Estrada do BemQuerer, Km 04 - Bairro Universitário - 45083-900 - Vitória da Conquista, BA - aviana@uesb.br; snaomi@uesb.br

3Engenheiro Agrônomo, Mestre - Avenida Franklin Ferraz, 1251, Candeias - 45055-075 - Vitória da Conquista, BA - hermes.bn@bol.com.br ${ }^{4}$ Engenheira Agrônoma, Mestre - Avenida Campo Grande, 373, Candeias - 45050-430 - Vitória da Conquista, BA - camilakhouri@yahoo.com.br ${ }^{5}$ Engenheiro Agrônomo, Mestre, Pesquisador - Departamento de Fitotecnia e Zootecnia/DFZ - Universidade Estadual do Sudoeste da Bahia/UESB Estrada do Bem-Querer, Km 04 - Bairro Universitário - 45083-900 - Vitória da Conquista, BA - thiagolimelo@bol.com.br
} 
O consumo desta hortaliça é feito de diversas formas, sendo a mais tradicional na forma cozida, consumida com ou sem uso de temperos, substituindo o pão e outros alimentos no café da manhã. A batata cozida e amassada é utilizada como ingrediente principal ou como substituto parcial da farinha de trigo na confecção de doces e salgados tais como: purê, pastel, torta salgada, bala, bolo, pudim, torta doce, entre outros (SILVA et al., 2006).

A batata-doce é um alimento energético. Ao ser colhida, apresenta cerca de $30 \%$ de matéria seca que contém em média $85 \%$ de carboidratos, cujo componente principal é o amido. Comparada com outras estruturas vegetais amiláceas possui maior teor de matéria seca, carboidratos, lipídios, cálcio e fibras que a batata, mais carboidratos e lipídios que o inhame e mais proteína que a mandioca (CLARK \& MOYER, 1988; FOLQUER, 1978; WOOLFE, 1992).

Apesar de sua importância, são poucos os trabalhos de pesquisas visando selecionar e recomendar cultivares de batata-doce para diferentes regiões do país. Sabe-se que tanto a introdução quanto a obtenção de cultivares, de qualquer espécie cultivada, constitui um trabalho contínuo e dinâmico, pois as novas cultivares selecionadas permanecem em uso durante alguns anos, para serem substituídas por outras superiores (SILVA \& LOPES, 1995).

Neste trabalho, objetivou-se avaliar características físicas e sensoriais de clones de batata-doce provenientes de diferentes locais e cultivados em Vitória da Conquista - BA.

\section{MATERIAL E MÉTODOS}

O experimento foi realizado na Área Experimental do Campus da Universidade Estadual do Sudoeste da Bahia (UESB), em Vitória da Conquista - BA, a 14 53'51" latitude sul e 40 48'23" longitude oeste, à altitude média de 900m.

Os clones de batata-doce utilizados foram provenientes do Banco de Germoplasma da Empresa de Pesquisa Agropecuária de Minas Gerais - EPAMIG e da Universidade Federal de Viçosa - UFV e coletados junto a agricultores da região. Os clones são citados e classificados pelo local de origem, segundo Oliveira (2002): Clones 1, 2, 7, 9, 14, 15 e 17 (Janaúba-MG); Clone 19 (Viçosa-MG); Clones 23 e 25 (Bom Jardim de Minas - MG); Clones 29 e 30 (Gurupi - TO); Clone 36 (Santo Antônio da Platina PR); Clone 38 (Holambra II - SP); Clone 44 (Vitória da Conquista - BA) e Clone 100 (Condeúba-BA).

O solo foi preparado de acordo com o recomendado para a cultura, não sendo feitas calagem e adubação para simular ambiente que prevalece nas áreas de cultivo dessa cultura.
O plantio foi feito em leiras, com $30 \mathrm{~cm}$ de altura, com espaçamento de $1,5 \mathrm{~m}$ x $0,25 \mathrm{~m}$. Utilizaram-se ramas selecionadas e padronizadas (segmentos com $50 \mathrm{~cm}$ de comprimento). Os tratos culturais (capinas e irrigações) foram feitos sempre que necessários, no decorrer do experimento.

O delineamento experimental utilizado foi em blocos casualizados, com 16 tratamentos (clones) e três repetições, sendo a parcela experimental composta por 6 plantas úteis.

Após a colheita, feita 7 meses após o plantio, as plantas foram levadas para o Laboratório de Tecnologia de Alimento para as avaliações física e sensorial.

A avaliação sensorial compreendeu os atributos aparência (não atrativa, pouco atrativa e atrativa), umidade (seco, médio e úmido), doçura (forte, média e fraca), coloração da polpa (branca, amarela e roxa) e dificuldade de deglutição das raízes tuberosas (maior, menor e nenhuma), feita por um grupo de provadores não treinado que atribuíram notas às características conforme Souza (2000). As características sensoriais foram expressas em porcentagem.

A avaliação física foi feita por meio do tempo de cozimento, determinado pelo método proposto por Souza (2000). Inicialmente, as raízes tuberosas foram cortadas em fatias de $2 \mathrm{~cm}$ de espessura e $8 \mathrm{~cm}$ de diâmetro, e, em seguida, colocadas em três panelas de alumínio, com capacidade de 4,5 litros em chamas médias e uniformes, contendo 2,3 litros de água corrente. Após o início da fervura da água, o tempo de cozimento foi determinado por meio de toques com faca de ponta fina, estabelecendose, portanto, quando o material tornou-se cozido e macio. Além disso, avaliou-se também o peso específico, pelo método descrito pelo CIP (2001), sendo as raízes tuberosas de cada clone lavadas para retirar o excesso de terra, secas com papel toalha, e, em seguida, descartadas as suas extremidades. Procedeu-se à pesagem de $3 \mathrm{~kg}$ de raízes no ar, e, posteriormente foi feita a pesagem na água, determinando-se assim, o peso específico pelo método da balança hidrostática com base na seguinte fórmula: Peso específico = Peso no ar/(peso no ar - peso na água).

A análise estatística foi realizada utilizando-se o programa SAEG, versão 8.0, procedendo-se à Análise de Variância e, posteriormente, as médias dos tratamentos foram agrupadas usando-se o procedimento proposto por Scott-Knott a 5\% de probabilidade. A homogeneidade de variâncias dos dados foi verificada usando-se o teste de Cochran e, de acordo com a necessidade, estes foram transformados em $\sqrt{\mathrm{x}+0,5}$. 


\section{RESULTADOS E DISCUSSÃO}

Observa-se na Tabela 1 que predominou o conteúdo de umidade média e o úmido, sendo os clones 1, 2, 7, 9, 14, 15, 19, 23, 25, 29, 44 e 100 classificados como conteúdo de umidade média. Apenas os clones 17, oriundo de Janaúba -MG, 30, oriundo de Gurupi - TO e 38, oriundo de Holambra II - SP apresentaram alto conteúdo de umidade nas raízes tuberosas. Para Souza (2000), as raízes de batata-doce que apresentam conteúdo de umidade entre o seco e o médio são consideradas as melhores. Entretanto, para a região Nordeste, a preferência é também por batata-doce com menos umidade e maior matéria seca, sendo o clone 36 uma boa opção para esta região.

A coloração da polpa de raiz de batata-doce varia de branca, amarela até a roxa, sendo uma característica de importância para a comercialização da mesma. Neste trabalho, foi constatado que os clones $1,2,7,9,15,17,19$, 29, 36 e 38 apresentaram coloração da polpa amarela; os clones 14, 23, 25, 30 e 100 apresentaram coloração da polpa branca e apenas o clone 44, oriundo de Vitória da Conquista - BA apresentou coloração roxa, que não é muito aceita (Tabela 1). Conforme Miranda et al. (1995), as raízes comercializadas nos grandes centros urbanos apresentam coloração de polpa branca ou amarela. Assim, geralmente as raízes tuberosas consideradas de boa aparência, são as que apresentam estas colorações.

O grau de doçura da polpa dos clones $1,15,17,19$, $25,29,30,36$ e 100 foi considerado médio, enquanto que apenas os clones 9, 14 e 44 apresentaram fraca doçura da polpa (Tabela 2). Os clones 2, 7 e 38 foram classificadas entre o forte e o médio (Tabela 2). De acordo com Souza (2000), o grau de doce considerado satisfatório está entre o forte e o médio. Portanto, a maioria dos clones analisados apresentou bom grau de doçura.

$\mathrm{Na}$ Tabela 2, pode-se verificar que nenhum clone apresentou maior grau de dificuldade de deglutição. Os clones $9,14,19,23,36,44$ e 100 apresentaram uma menor dificuldade na deglutição; já os clones $2,7,17,25,29$ e 38 não apresentaram esta característica, sendo estes considerados os melhores neste aspecto. Os clones 1, 15 e 30 apresentaram uma classificação entre menor e nenhuma dificuldade de deglutição. Além disso, pode-se verificar que os clone 17 e 7 (oriundos de Janaúba - MG) e 29 (Gurupi - TO) foram os que apresentaram a maior porcentagem em relação a nenhuma dificuldade de deglutição, com 90, 80 e $80 \%$, destacando-se assim dos demais clones quanto a essa característica.

Tabela 1 - Características culinárias de raízes de clones de batata-doce. UESB, Vitória da Conquista, BA 2007.

\begin{tabular}{|c|c|c|c|c|c|c|}
\hline \multirow{2}{*}{ Clone } & \multicolumn{3}{|c|}{ Umidade $(\%)$} & \multicolumn{3}{|c|}{ Coloração da polpa (\%) } \\
\hline & Seco & Médio & Úmido & Branca & Amarela & Roxa \\
\hline 1 (Janaúba - MG) & 0 & 90 & 10 & 30 & 70 & 0 \\
\hline 2 (Janaúba - MG) & 10 & 60 & 30 & 0 & 100 & 0 \\
\hline 7 (Janaúba - MG) & 0 & 80 & 20 & 20 & 80 & 0 \\
\hline 9 (Janaúba - MG) & 30 & 50 & 20 & 10 & 90 & 0 \\
\hline 14 (Janaúba - MG) & 30 & 50 & 20 & 80 & 20 & 0 \\
\hline 15 (Janaúba - MG) & 30 & 50 & 20 & 0 & 100 & 0 \\
\hline 17 (Janaúba - MG) & 0 & 40 & 60 & 10 & 90 & 0 \\
\hline 19 (Viçosa - MG) & 10 & 90 & 0 & 0 & 100 & 0 \\
\hline 23 (Bom Jardim de Minas - MG) & 30 & 60 & 10 & 90 & 10 & 0 \\
\hline 25 (Bom Jardim de Minas - MG) & 30 & 50 & 20 & 100 & 0 & 0 \\
\hline 29 (Gurupi - TO) & 30 & 60 & 10 & 20 & 80 & 0 \\
\hline 30 (Gurupi - TO) & 30 & 30 & 40 & 90 & 10 & 0 \\
\hline 36 (Santo Antônio de Platina - PR) & 50 & 50 & 0 & 20 & 80 & 0 \\
\hline 38 (Holambra II - SP) & 30 & 20 & 50 & 20 & 80 & 0 \\
\hline 44 (Vitória da Conquista - BA) & 20 & 70 & 10 & 0 & 0 & 100 \\
\hline 100 (Condeúba - BA) & 40 & 50 & 10 & 90 & 10 & 0 \\
\hline
\end{tabular}

Ciênc. agrotec., Lavras, v. 31, n. 6, p. 1760-1765, nov./dez., 2007 
Tabela 2 - Características culinárias de raízes de clones de batata-doce, UESB, Vitória da Conquista, BA 2007.

\begin{tabular}{lccccccc}
\hline & \multicolumn{3}{c}{ Doçura da polpa (\%) } & \multicolumn{2}{c}{ Dificuldade de deglutição (\%) } & \multicolumn{2}{c}{$\begin{array}{c}\text { Tempo de } \\
\text { cozimento (min) }\end{array}$} \\
\cline { 2 - 6 } & Forte & Média & Fraca & Maior & Menor & Nenhuma & cozime \\
\hline 1 (Janaúba - MG) & 10 & 80 & 10 & 0 & 50 & 50 & $18,0 \mathrm{e}$ \\
2 (Janaúba - MG) & 40 & 40 & 20 & 20 & 20 & 60 & $13,3 \mathrm{f}$ \\
7 (Janaúba - MG) & 40 & 40 & 20 & 10 & 10 & 80 & $10,3 \mathrm{i}$ \\
9 (Janaúba - MG) & 10 & 10 & 80 & 20 & 60 & 20 & $14,3 \mathrm{e}$ \\
14 (Janaúba - MG) & 10 & 40 & 50 & 30 & 50 & 20 & $16,0 \mathrm{~d}$ \\
15 (Janaúba - MG) & 20 & 60 & 20 & 0 & 50 & 50 & $14,0 \mathrm{e}$ \\
17 (Janaúba - MG) & 40 & 60 & 0 & 0 & 10 & 90 & $12,7 \mathrm{f}$ \\
19 (Viçosa - MG) & 20 & 70 & 10 & 10 & 60 & 30 & $20,0 \mathrm{a}$ \\
23 (Bom Jardim de Minas - MG) & 20 & 40 & 40 & 10 & 50 & 40 & $19,0 \mathrm{~b}$ \\
25 (Bom Jardim de Minas - MG) & 30 & 60 & 10 & 30 & 30 & 40 & $14,7 \mathrm{e}$ \\
29 (Gurupi - TO) & 30 & 60 & 10 & 0 & 20 & 80 & $13,0 \mathrm{f}$ \\
30 (Gurupi - TO) & 0 & 60 & 40 & 0 & 50 & 50 & $11,7 \mathrm{~g}$ \\
36 (Santo Antônio de Platina - PR) & 0 & 60 & 40 & 30 & 60 & 10 & $16,3 \mathrm{~d}$ \\
38 (Holambra II - SP) & 50 & 50 & 0 & 20 & 20 & 60 & $13,0 \mathrm{f}$ \\
44 (Vitória da Conquista - BA) & 0 & 30 & 70 & 20 & 50 & 30 & $13,0 \mathrm{f}$ \\
100 (Condeúba - BA) & 0 & 60 & 40 & 10 & 50 & 40 & $11,0 \mathrm{~h}$ \\
\hline
\end{tabular}

*Médias seguidas de mesma letra, na coluna, não diferem entre si a 5\% de probabilidade pelo teste de Scott-Knott.

$\mathrm{Na}$ Tabela 2, observa-se que houve efeito significativo nos clones para a característica tempo de cozimento. O clone 7, oriundo de Janaúba-MG, teve menor tempo de cozimento em relação aos demais, ou seja, necessitou de apenas 10 minutos para estar cozido, enquanto que o clone 19, oriundo de Viçosa-MG, precisou do dobro do tempo para cozinhar. De acordo com Souza (2000), o tempo de cozimento do clone 7 é considerado pequeno e isso é um indicativo de boa característica culinária desse material.

O aspecto da raiz tuberosa é um atributo utilizado pelos consumidores. Geralmente, as batatas-doces mais preferidas são as lisas, bem conformadas e de formato alongado (MIRANDA et al., 1995). Neste trabalho, constatou-se que os clones 7, 9, 15, 17, 25, 36, 38 e 100 apresentaram melhor aspecto da raiz tuberosa, enquanto que as raízes dos clones 14, 19, 29 e 30 foram consideradas pouco atrativas (Tabela 3). Apenas o clone 2, oriundo de Janaúba- MG e o clone 44, oriundo de Vitória da Conquista - BA apresentaram $40 \%$ da nota quanto ao aspecto da raiz - não atrativa. Os clones 25, 100, 7, 15 e 36 foram os clones considerados mais atrativos. $\mathrm{O}$ aspecto da raiz tuberosa é uma característica que poderá ser utilizada como forma de determinação de um padrão comercial de raízes de batata-doce.

O peso específico de raiz variou de 1,00 a 1,08. Os dados de peso específico não foram submetidos à análise estatística, pois para avaliar esta característica utilizouse uma amostra de raízes tuberosas das três repetições. Foi observado que o clone 15 apresentou maior peso específico $(1,08)$ seguido pelos clones 1 e $30(1,07$ e 1,06, respectivamente) (Figura 1). Morais \& Pinto (1996), avaliando clones híbridos de batata (Solanum tuberosum L. x Solanun chacoense Bitt), encontraram média geral de 1,091 para peso específico. Estes autores encontraram correlação e concluíram que a seleção de clones produtores de tubérculos graúdos não é bom critério na obtenção de tubérculos com alto peso específico.

Essa característica é considerada importante para determinar a aptidão culinária. Os clones apresentam variabilidade para uso culinário, prestandose para fritura aqueles com alto peso específico e cozimento os de baixo peso específico (MORAIS \& PINTO, 1996). 
Tabela 3 - Aspecto da raiz tuberosa de clones de batata-doce, UESB, Vitória da Conquista, BA 2007.

\begin{tabular}{|c|c|c|c|}
\hline \multirow{2}{*}{ Clone } & \multicolumn{3}{|c|}{ Aspecto da raiz (\%) } \\
\hline & Não atrativa & Pouco atrativa & Atrativa \\
\hline 1 (Janaúba - MG) & 0 & 50 & 50 \\
\hline 2 (Janaúba - MG) & 40 & 20 & 40 \\
\hline 7 (Janaúba - MG) & 0 & 30 & 70 \\
\hline 9 (Janaúba - MG) & 10 & 30 & 60 \\
\hline 14 (Janaúba - MG) & 0 & 60 & 40 \\
\hline 15 (Janaúba - MG) & 0 & 30 & 70 \\
\hline 17 (Janaúba - MG) & 0 & 40 & 60 \\
\hline 19 (Viçosa - MG) & 10 & 60 & 30 \\
\hline 23 (Bom Jardim de Minas - MG) & 0 & 50 & 50 \\
\hline 25 (Bom Jardim de Minas - MG) & 0 & 10 & 90 \\
\hline 29 (Gurupi - TO) & 10 & 70 & 20 \\
\hline 30 (Gurupi - TO) & 20 & 60 & 20 \\
\hline 36 (Santo Antônio de Platina - PR) & 0 & 30 & 70 \\
\hline 38 (Holambra II - SP) & 10 & 40 & 50 \\
\hline 44 (Vitória da Conquista - BA) & 40 & 40 & 20 \\
\hline $100($ Condeúba - BA $)$ & 0 & 20 & 80 \\
\hline
\end{tabular}

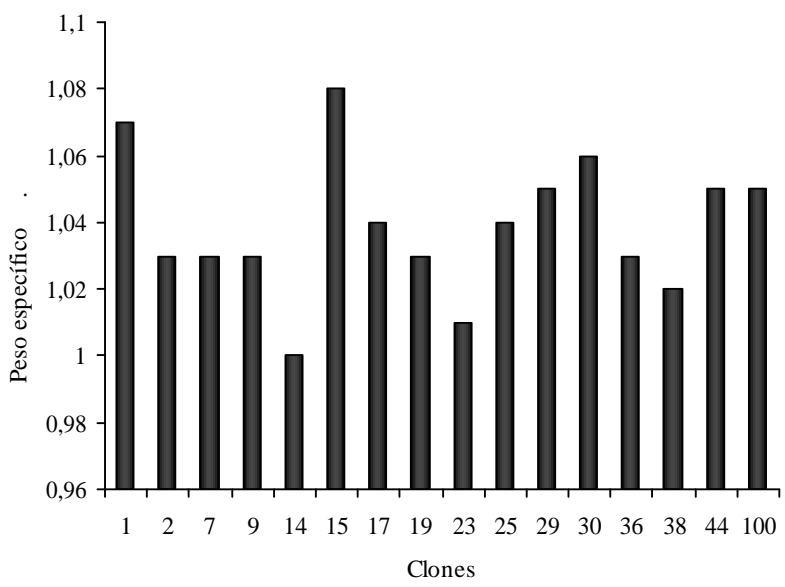

Figura 1 - Peso específico de clones de batata-doce, UESB, Vitória da Conquista, BA 2007.

\section{CONCLUSÕES}

O clone 25 apresentou as melhores características culinárias, pois foi o único clone que se enquadrou em todas as características desejáveis da avaliação da degustação.
O clone 7 apresentou menor tempo de cozimento.

\section{AGRADECIMENTOS}

Os autores agradecem à Universidade Estadual do Sudoeste da Bahia (UESB) e à Coordenação de Aperfeiçoamento do Pessoal de Nível Superior (CAPES).

\section{REFERÊNCIAS BIBLIOGRÁFICAS}

CENTRO INTERNACIONAL DE LA PAPA - CIP. La batata em cifras: producción, utilización, consumo e alimentación. Disponível em: <http//:www.cipotato.org>. Acesso em: 3 jul. 2001.

CLARK, C. A.; MOYER, J. W. Compendium of sweet potato diseases. Saint Paul: APS, 1988. 74 p.

FOLQUER, F. La batata (camote): estudio de la planta y su producción comercial. San Jose: [s.n.], 1978. 144 p.

FOOD AND AGRICULTURE ORGANIZATION OF THE UNITED NATIONS. Dados agrícolas de 2005. Disponível em: <http://www.fao.org/>. Acesso em: 30 abr. 2007. 
MIRANDA, J. E. C. de; FRANÇA, F. H.; CARRIJO, O. A.; SOUZA, A. F. Batata-doce. Brasília, DF: Embrapa-CNPH, 1987. 14 p.

MIRANDA, J. E. C. de; FRANÇA, F. H.; CARRIJO, O. A.; SOUZA, A. F.; PEREIRA, W.; LOPES, C. A.; DILVA, J. B. C. A cultura da batata-doce. Brasília, DF: Embrapa /CNPH, 1995. 94 p.

MIRANDA, J. E. C. de; FRANÇA, F. H.; CARRIJO, O. A.; SOUZA, A. F.; PEREIRA, W.; LOPES, C. A.; DILVA, J. B. C. Batata-doce (Ipomoea batatas (L.) Lam.). 2. ed. Brasília, DF: Embrapa/CNPH, 1989. 19 p.

MORAIS, O. M.; PINTO, C. A. B. P. Selection for yield, tuber specific gravity and high $2 \mathrm{n}$ pollen production in potato hybrids between Solanun tuberosum L. and the wild species Solanum chacoense Bitt. Brazilian Journal of Genetics, São Paulo, v. 19, n. 3, p. 459-463, 1996.

MURILO, D. V. Aspectos econômicos da batata-doce. In: ENCONTRO DE PROFESSORES, PESQUISADORES E
EXTENCIONISTAS DO RIO GRANDE DO NORTE, 4., 1999, Mossoró. Anais... Mossoró: ESAM, 1999. p. 21-28.

OLIVEIRA, A. C. B de; DEDIYAMA, M. A. N.; SEDIYAMA, T.; FINGER, F. L.; CRUZ, C. D. Variabilidade genética em batatadoce com base em marcadores isoenzimáticos. Horticultura Brasileira, Brasília, v. 20, n. 4, p. 576-582, dez. 2002.

SILVA, J. B. C.; LOPES, C. A. Cultivo da batata-doce. 3. ed. Brasília, DF: Embrapa, 1995. 18 p. (Instruções técnicas de CNPHortalilças, 7).

SILVA, J. B. C. da; LOPES, C. A.; MAGALHÃES, J. S. Cultura da batata-doce. Disponível em: <http:// www.cnph.embrapa.br/>. Acesso em: 11 jan. 2006.

SOUZA, A. B. de. Avaliação de cultivares de batata-doce quanto atributos agronômicos desejáveis. Ciência e Agrotecnologia, Lavras, v. 24, n. 4, p. 841-845, out./dez. 2000.

WOOLFE, J. A. Sweet potato: an untapped food resource. Cambridge: Cambridge University, 1992. 188 p. 